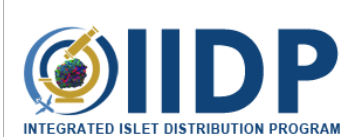

VERSION 4

SEP 09, 2020

\section{OPEN ØAACESS}

DOI:

dx. doi.org/10.17504/protocol s.io.bk5vky66

Protocol Citation: Integrated Islet Distribution Program 2020. Qualitative \&

Quantitative Assessment of Human Islets for Distribution Using Dithizone (DTZ).

protocols.io

https://dx. doi.org/10.17504/p

rotocols.io.bk5 vky66Version created by Integrated Islet

Distribution Program

MANUSCRIPT CITATION:

License: This is an open access protocol distributed under the terms of the Creative Commons Attribution License, which permits unrestricted use, distribution, and reproduction in any medium, provided the original author and source are credited

Protocol status: Working We use this protocol and it's working

Created: Sep 08, 2020

Last Modified: Sep 09, 2020

PROTOCOL integer ID: 41877

Keywords: Human Islets, Dithizone, Purity, Islet Equivalent, Actual Islet, Islet Quality Grade, Islet Index, Islets of Langerhans, human islets, islet equivalent

\section{(7) Qualitative \& Quantitative Assessment of Human Islets for Distribution Using Dithizone (DTZ) V.4}

In 1 collection

Integrated Islet Distribution Program ${ }^{1}$

${ }^{1}$ Integrated Islet Distribution Program, City of Hope, Duarte, CA

Integrated Islet Distribution Program Integrated Islet Distribution Program and Human Islet Phenotyping Prog

Integrated Islet Distribution Program

Integrated Islet Distribution Program, City of Hope

\section{ABSTRACT}

This Standard Operating Procedure is adapted from the work of the 'National Institutes of Health-Sponsored Clinical Is/et Transplantation Consortium Phase 3 Trial: Manufacture of a Complex Cellular Product at Eight Processing Facilities"following the SOP cited in the document 'Purified Human Pancreatic Islet: Qualitative and Quantitative Assessment of Is/ets Using Dithizone (DTZ) - Standard Operating Procedure of the NIH Clinical/slet Transplantation Consortium'

This SOP defines the assay method for quantitative and qualitative determination in the identification of human isolated islet preparations, which include endocrine and exocrine tissue, for use in the National Institute of Diabetes and Digestive and Kidney Diseases (NIDDK) sponsored research in the Integrated Islet Distribution Program (IIDP). This protocol is written to assist the participating islet isolation centers and investigators who are part of this program.

Note

Notice: This SOP corrects an error which has been discovered on the conversion factor of islets to IEQ for the 101-150 range in Step 4.3 and on Attachment 1. The conversion factor should be 0.648 not 0.667 . We apologize for the error, but the discrepancy in the conversion factor was difficult to trace historically, hence the importance for Rigor and Reproducibility provided by protocols.io. Documentation of this revision is found in Kin T. (2010) Islet Isolation for Clinical Transplantation. The Is/ets of Langerhans. Advances in Experimental Medicine and Biology. Volume 654.Dordrecht: Springer; p 683-710 referenced below.

Note

Integrated Islet Distribution Program (IIDP) (RRID:SCR_014387)

Dithizone (diphenyl thiocarbazone; DTZ) is an organic chemical that chelates the zinc in the insulin granules present in the beta cells of the pancreatic islets. The islet cells are stained red while the acinar cells remain unstained.

DTZ staining is used as a lot release and as an in-process assay:

(i)Lot release testing: DTZ staining is used to identify islets and to determine the quantity and quality of the final islet product. Islet quantity is expressed as the number of islet equivalents (IEQ), which is calculated based on the number and diameter of the islets present in the preparation, mathematically corrected for islet volume.

(ii)In-process testing: DTZ staining is used to identify islets and to assess the effectiveness of the digestion, isolation and purification processes. The quality of the preparations is expressed as percent islet purity, and percent trapped islets. Islet quantity (IEQ) is also assessed.

\section{GUIDELINES}

- Integrated Islet Distribution Program (IIDP) (RRID:SCR_014387): The IIDP is a contracted program commissioned and funded by the NIDDK to provide quality human islets to the diabetes research community to advance scientific discoveries and translational medicine. The IIDP consists of the NIDDK, the Project Officer (PO), the External Evaluation 
Committee (EEC) and the CC at City of Hope (COH). The IIDP CC integrates an interactive group of academic laboratories including the subcontracted IIDP centers.

- IIDP Coordinating Center (CC): Joyce Niland, Ph.D. is the Principal Investigator for the IIDP CC and leads staff from the Department of Research Information Sciences at $\mathrm{COH}$ to coordinate the activities of the IIDP and assist the participating centers and investigators in the distribution of human islets.

- Percent Purity. the percentage of islets compared to all tissue present in the islet preparation (islets, acinar and ductal cells) which is determined by visual inspection of a representative sample of the islet preparation. Islets are distinguished from non- islet tissue by using Dithizone (DTZ) to stain red the zinc granules in the beta cells.

- Actual Islets (AI) or Islet Particle Number (IPN): The actual number of islets or islet particles counted. For this SOP, the nomenclature of Actual Islets (Al) will be used.

- Islet Equivalent (IEQ) : An IEQ is defined as an islet with a diameter of 150 microns. The number of IEQ in each size class is calculated by multiplying the number of islets by a conversion factor for each size.

- Islet Quality Grade: A qualitative designation given to the islet preparation after microscopic evaluation based on the parameters of shape, border, integrity, number of single cells, and overall islet diameter.

\section{- Equations for Total Equivalent (Total IEQ) and Total Actual Islet(AI):}

1. Total IEQ $=$ Dilution Factor $x$

$[($ Al of diameter $50-100 \mu \mathrm{m} \times 0.167)+$

(Al of diameter $101-150 \mu \mathrm{m} \times 0.648)+$

(Al of diameter $151-200 \mu \mathrm{m} \times 1.685)+$

(Al of diameter $201-250 \mu \mathrm{m} \times 3.500)+$

(Al of diameter $251-300 \mu \mathrm{m} \times 6.315)+$

(Al of diameter $301-350 \mu \mathrm{m} \times 10.352)+$

(Al of diameter $>350 \mu \mathrm{m} \times 15.833$ )]

2. Total $\mathbf{A} \mathbf{I}=$ Dilution Factor $x \sum \mathrm{Al}$ of each diameter

- Islet Index (II): A quantitative designation given to the islet preparation after microscopic evaluation determined by dividing the IEQ by the AI. This designation determines the overall size distribution of the islets being shipped. If the majority of $\mathrm{Al}$ is around $150 \mu \mathrm{m}$ (1-IEQ) then the II will equal 1.0. If the majority of $\mathrm{Al}$ is larger than $150 \mu \mathrm{m}$, then the II will be $>1.0$. If the majority of the $\mathrm{Al}$ is smaller than $150 \mu \mathrm{m}$, then the II will be $<1.0$.

References:

\section{CITATION}

Ricordi, C. Gray, D. W. Hering, B. J. Kaufman, D. B. Warnock, G. L. Kneteman, N. M. Lake, S. P. London, N. J. Socci, C. Alejandro, R. et al., (1990). Islet isolation assessment in man and large animals. Acta Diabetol Lat, Vol 27, Issue 3, Pg 185-95.

LINK

https://doi.org/10.1007/BF02581331

\section{CITATION}

Ricordi, C (1992). Pancreatic Islet Cell Transplantation. Austin: R.G. Landes Company. 
Kin T. (2010). Islet Isolation for Clinical Transplantation. The Islets of Langerhans. Advances in Experimental Medicine and Biology. Volume 654.Dordrecht: Springer; p 683-710.

\section{CITATION}

NIH CIT Consortium Chemistry Manufacturing Controls Monitoring Committee, NIH CIT Consortium (2015). Purified Human Pancreatic Islet: Qualitative and Quantitative Assessment of Islets Using Dithizone (DTZ): Standard Operating Procedure of the NIH Clinical Islet Transplantation Consortium. CellR4- repair, replacement, regeneration, \& reprogramming. LINK

https://doi.org/pii:e1369

\section{CITATION}

Ricordi C, Goldstein JS, Balamurugan AN, Szot GL, Kin T, Liu C, Czarniecki CW, Barbaro B, Bridges ND, Cano J, Clarke WR, Eggerman TL, Hunsicker LG, Kaufman DB, Khan A, Lafontant DE, Linetsky E, Luo X, Markmann JF, Naji A, Korsgren O, Oberholzer J, Turgeon NA, Brandhorst D, Chen X, Friberg AS, Lei J, Wang LJ, Wilhelm JJ, Willits J, Zhang X, Hering BJ, Posselt AM, Stock PG, Shapiro AM, Chen X (2016). National Institutes of Health-Sponsored Clinical Islet Transplantation Consortium Phase 3 Trial: Manufacture of a Complex Cellular Product at Eight Processing Facilities. Diabetes, 2016 Nov, 65(11): 3418-28. PMCID: 5079635. LINK

http://www.ncbi.nlm.nih.gov/pubmed/27465220

\section{MATERIALS}

MATERIALS

88 Dithizone (Diphenylthiocarbazone) Millipore Sigma Catalog \#D5130

88 Gibco DPBS without Calcium and Magnesium Fisher Scientific Catalog \#14190136 or equivalent

88 Dimethyl sulfoxide Sigma Aldrich Catalog \#D8779 or equivalent 
Equipment

Gilson $^{\text {TM }}$ PIPETMAN Classic ${ }^{\mathrm{TM}}$ Pipets- F123601 or equivalent

NAME

Adjustable pipettor -P200

Gilson

BRAND

F123601G

https://www.fishersci.com/shop/products/gilson-pipetman-classic-pipets-model-p200-vol-50-200-l/f123601g

LINK

50 to $200 \mu \mathrm{L}, \pm 0.5, \pm 1 \mu \mathrm{L}$

SPECIFICATIONS

Equipment

Fisherbrand $^{\mathrm{TM}}$ Large-Orifice Pipet Tips, 1 to $200 \mu \mathrm{L}$ or equivalent

NAME

Genomic/Wide Orifice Pipet Tips

Fisherbrand

BRAND

$02-707-134$

SKU

https://www.fishersci.com/shop/products/fisherbrand-large-orifice-pipet-tips-6/02707134?keyword=true

1 to $200 \mu \mathrm{L}$

SPECIFICATIONS 
Equipment

Fisherbrand $^{\mathrm{TM}}$ Petri Dishes with Clear Lid or equivalent

Petri Dishes

Fisherbrand

FB0875713A

Round, Raised Ridge, 60mm, $15 \mathrm{~mm}$

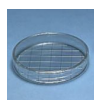

Equipment

Thermo Scientific $^{\mathrm{TM}}$ Nalgene $^{\mathrm{TM}}$ Rapid-Flow $^{\mathrm{TM}}$ Sterile Disposable Bottle Top Filters with PES Membrane or ${ }^{\text {NAME }}$ equivalent

0.45 um Bottle Top filter

Thermo Scientific

$09-740-62 \mathrm{C}$

https://www.fishersci.com/shop/products/nalgene-rapid-flow-sterile-disposable-bottle-top-filters-pesmembrane/0974062c

$0.45 \mu \mathrm{m}$ nylon Filter

Equipment

Invitrogen ${ }^{T M}$ EVOS $^{\mathrm{TM}} \mathrm{XL}$ Core Imaging System or equivalent

Inverted Microscope

Light Microscope

AMEX1000

https://www.fishersci.com/shop/products/evos-xl-core-imaging-system/12562751\#? 
Equipment

Lab inverted light microscope

NAME

Eyepiece with Calibrated reticle, $1 \mathrm{~mm}$

Microscope specific, lab SOP

Equipment

Bal Supply Cell Counter or equivalent

Cell Counter (Manual or Electronic)

Bal Supply

BRAND

02-670-14

SKU

https://www.fishersci.com/shop/products/bal-supply-cell-counters-4/0267014

Equipment

Drummond $^{\mathrm{TM}}$ Fixed-Volume Microdispensers or equivalent

Drummond 3000385

Drummond $^{\text {TM }}$

BRAND

$21176 \mathrm{~F}$

https://www.fishersci.com/shop/products/drummond-fixed-volume-microdispensers-16/21176f? searchHijack=true \&searchTerm=21176F \&searchType=RAPID \&matchedCatNo=21176F

Volumetric Range 100/200UL with borosilicate glass bores 


\section{SAFETY WARNINGS}

(1) Dimethyl sulfoxide (DMSO) $\square$ DMSO_MSDSAction.pdf

- Hazard statement(s): Combustible liquid.

- Precautionary statement(s): Keep away from heat/sparks/open flames/hot surfaces. No smoking. Wear protective gloves/ protective clothing/ eye protection/ face protection.

- DMSO itself is not toxic but it can be a carrier of chemicals, viruses, etc. into the skin

\section{Dithizone (DTZ) $\square$ Dithizone_MSDSAction.pdf}

- Hazard Statement(s): Causes skin irritation. Causes serious eye irritation.

- Precautionary statement(s): Wash skin thoroughly after handling. Wear protective gloves/ eye protection/ face protection.

\section{Preparation of Working Dithizone}

1 Assemble all items described in the Materials section.

2 Prepare DTZ stain as described below. Observe all safety precautions when working with DMSO.

2.1 Dissolve \ $50 \mathrm{mg}$ dithizone in \ $10 \mathrm{~mL}$ DMSO.

2.2 Add DPBS to bring the total volume to $\triangle 50 \mathrm{~mL}$

2.3 Filter the combined solution using a $0.45 \mu \mathrm{m}$ nylon filter. 
2.4 Place solution in a $50 \mathrm{~mL}$ conical tube and label "Dithizone Stain or DTZ" with:

- Preparation Date and Time

- Expiration Date and Time (24 hours after preparation)

- Initials of person preparing solution

\section{Preparation of Islets for Counting}

3 Samples for islet quantitation and purity should be taken for islet broadcast either after the isolation or post culture. Sampling must be repeated prior to packaging for shipment in order to ensure that samples after culture are representative of what is being distributed to the investigators.

3.1 Mix the final islets suspension very gently but thoroughly by inverting the islet prep in a conical 2-3 times before quickly taking a sample. (Do not swirl.) As islets settle rapidly, care must be taken to ensure a representative sample is taken from the middle of the suspension.

3.2 Take replicate $100-200 \mu \mathrm{L}$ sample volumes from $100 \mathrm{~mL}$ final prep using a widebore tip pipettor. Two duplicate counts should be performed by two separate technicians or 2 separate counts by one technician.

3.3 Add 3 drops $(30 \mu \mathrm{L})$ of the DTZ solution to the islets sample and allow staining for $1-2$ minutes at room temperature. Cover the bottom of the counting dish with DPBS to approximately $1 / 2$ the height of the dish. Count the islets under the microscope following the steps below.

\section{Islet Quantification}

Identify AI, IEQ, and \% purity.

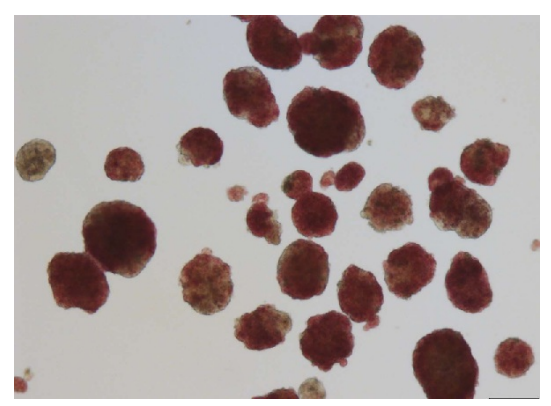

Dithizone Stained Islets

Note

Dithizone (diphenyl thiocarbazone; DTZ) is an organic chemical that chelates the zinc in the insulin granules present in the beta cells of the pancreatic islets. The islet cells are stained red while the acinar cells remain unstained. 
- Islets are counted by size of the Actual Islets (Al), tabulated, and mathematically calculated to determine the Total Islet Equivalents (IEQ).

- Examine the islets sample (stained islets will appear red) using the $10 x$ eyepiece and the $4 x$ objective to give a total magnification of $40 x$.

- Using the grid lines on the counting dish as a guide, methodically scroll through the dish from side to side, and top to bottom, examining each islet.

- Count islets within the perimeter of the grid's squares, including only islets touching the top and right lines (not the bottom and left lines), to avoid counting the same islet twice.

4.1 There are different types of reticles that can be used but all should be certified in the eyepiece to the correct specification by the microscope company representative. Once calibrated, the eyepiece of the microscope is used to determine the size of each islet.

Using the table below as a guide, regardless of which type of reticle is used, count (tally) the number of Actual Islets (AI) in each diameter group using the manual or electronic cell counter. Do not count islets smaller than $50 \mu \mathrm{m}$ because their contribution is not significant.

\begin{tabular}{|c|c|}
\hline $\begin{array}{c}\text { Number of } \\
\text { Spaces Spanned }\end{array}$ & $\begin{array}{c}\text { Diameter of } \\
\text { Islet }(\mu \mathrm{m})\end{array}$ \\
\hline$<2$ & $<50$ \\
\hline $2-4$ & $50-100$ \\
\hline $4-6$ & $101-150$ \\
\hline $6-8$ & $151-200$ \\
\hline $8-10$ & $201-250$ \\
\hline $10-12$ & $251-300$ \\
\hline $12-14$ & $301-350$ \\
\hline$>14$ & $>350$ \\
\hline
\end{tabular}

4.2 Calculate the dilution factor as follows:

Example for a $100 \mu \mathrm{L}$ sample from a $100 \mathrm{~mL}$ total volume $=1000$ dilution factor

Expected result

Dilution Factor $=[(\mathrm{mL}$ total volume $/ \mu \mathrm{L}$ sample volume $) \times 1000]$

4.3 Record and calculate the results using Excel Spreadsheet in Attachment 1. 


\begin{tabular}{|c|c|c|c|}
\hline $\begin{array}{c}\text { Islet Diameter } \\
\text { Range }(\mu \mathrm{m})\end{array}$ & $\begin{array}{c}\text { Islet Particle } \\
\text { Number (IPN) }\end{array}$ & $\begin{array}{c}\text { IEQ Conversion } \\
\text { Factor } \\
\end{array}$ & IEQ per Range \\
\hline $50-100$ & 11 & $\mathrm{X} 0.167$ & 1.84 \\
\hline $101-150$ & 42 & $\mathrm{X} 0.648$ & 27.22 \\
\hline $151-200$ & 26 & X 1.685 & 43.81 \\
\hline $201-250$ & 13 & X 3.500 & 45.50 \\
\hline $251-300$ & 5 & $\mathrm{X} 6.315$ & 31.58 \\
\hline $301-350$ & 0 & $\mathrm{X} 10.352$ & 0.00 \\
\hline$>350$ & 1 & $\mathrm{X} 15.833$ & 15.83 \\
\hline$\sum \mathrm{AI}$ & 95 & $\sum$ IEQ & 165.77 \\
\hline \multicolumn{3}{|c|}{ Dilution Factor [(mL total volume / $\mu \mathrm{L}$ sample volume $) \mathrm{X} 1000]$} & 1000 \\
\hline \multicolumn{3}{|c|}{ Total AI = $\sum$ AI X Dilution Factor } & 98,000 \\
\hline \multicolumn{3}{|c|}{ Total IEQ = $\sum$ IEQ X Dilution Factor } & 165,771 \\
\hline
\end{tabular}

\section{Example for a $100 \mu \mathrm{L}$ sample from a $100 \mathrm{~mL}$ total volume}

- Calculate the Total Actual Islets ( $\Sigma \mathrm{Al})$, and the Total Islet Equivalents $(\Sigma \mathrm{IEQ})$ by inputting the data from the tally, in step 4.1, into the Excel spreadsheet in Attachment 1 for Most Pure Shipment and Least Pure Shipment if applicable.

- Calculate the total number of IEQ present by entering the total Actual Islets (AI) in each range which will be converted using the conversion factor, to IEQ per each range. This conversion normalizes the Al to $150 \mu \mathrm{m}$ sized islet.

- Both the AI and IEQ will be totaled and multiplied by the dilution Factor for a Final AI count and Final IEQ Count of the preparation.

- The Islet Index (II), a calculation made by dividing the IEQ by the Al, is calculated automatically in Attachment 1 . This designation determines the overall size distribution of the islets being shipped.

- Repeat process, as needed, for a Least Pure Shipment.

\section{Attachment 1-Islet Tabulation Counting Sheet for Culturing Islets 2020.xlsx}

\section{Islet Quality Grade by Islet Ranking}

5 Determine the Islet Quality Grade based on the chart below and Islet Ranking Guide (Attachment 2). Record and calculate the results on

\begin{tabular}{|c|c|c|c|}
\hline Parameter & 0 Points & 1 Point & 2 Points \\
\hline Shape (3D) & flat/planar & in between & spherical \\
\hline Border (2D) & irregular & in between & well-rounded \\
\hline Integrity & fragmented & in between & Solid/compact \\
\hline Single Cells & many & a few & almost none \\
\hline Diameter & all $<100 \mu \mathrm{m}$ & a few $>200 \mu \mathrm{m}$ & $>10 \%>200 \mu \mathrm{m}$ \\
\hline
\end{tabular}




\section{Islet Purity}

6 Calculate the percent purity of the islets to the nearest $5 \%$ by estimating the portion of dithizone (red stained islets) to all tissue (islets, acinar, ductal cells). Record the purity of each sample on Attachment 1 . The average will be calculated automatically.

\section{Photographic Documentation}

7 Take digital images and upload (when applicable) for IIDP Islet Broadcast of the count sample.

7.1 Gently swirl the count sample in order to center the islets in the dish. This will give a representative photographic image of the purity and size distribution of the islet preparation. If possible, take a well focused digital photo, using the center's SOP for it's specific microscope and camera set-up, so the final image size is a 10x-40x magnification. Label and save image with RRID\#, date, time when photo was taken (prior to broadcast), and magnification.

7.2 With the use of the digital imaging techniques on the IIDP website, upload images and match the background grid lines per the online instructions in the broadcast section (when applicable).

\section{Subsequent Counting, Grading, Purity, and Viability}

8 Repeat all counting, grading, purity, and viability estimates and digital image uploads for islets prior to packaging for distribution if more than 6 hours post original broadcast evaluations. Update broadcast records under the "Confirm Islet Information" section of the broadcast and repeat these procedures for rebroadcasts and shipments with every subsequent 24 hour rebroadcast/shipment. 